\title{
The Interactional Approach in the Treatment of Cocaine Addicts
}

\author{
Andrea Leonardi, Sonia Scavelli and Gianluca Ciuffardi \\ Fondazione Franceschi Onlus, \\ Italy
}

"A living system, due to its circular organization, is an inductive system and functions always in a predictive manner; what occurred once will occur again. Its organization (both genetic and otherwise) is conservative and repeats only that which works."

Humberto Maturana

\section{Introduction}

Over the last few years cocaine use has spread considerably to all social levels. According to statistical data currently available, cocaine is the psychoactive substance most frequently used in Europe, after cannabis (European Monitoring Centre for Drugs and Drug Addiction [EMDDA], 2011). Italy is one of the European countries where such consumption is more frequent: about $7 \%$ of the population report to have used cocaine at least once in their lifetime (Presidenza del Consiglio dei Ministri, 2007).

Cocaine is an alkaloid substance obtained from coca leaves, which acts on the central nervous system, especially on the dopamine system, compromising its functions. Cocaine use contributes to increased concentration of dopamine, a neurotransmitter that is present in different brain areas that governs cognition, emotional processes, motivation and associative processes related to feelings of pleasure. Normally, this neurotransmitter is released by neurons in response to a salient, pleasant stimuli, and then it is absorbed by the same cells that have produced it. Cocaine acts on these cells by blocking the recovery of dopamine, resulting in an accumulation of the neurotransmitter between synapses.

Repeated cocaine use damages the normal communication between neurons, leading to alterations in brain circuits for pleasure that is thought to contribute to the development of dependence. In addition, the brain needs progressively higher doses of the psychoactive substance to achieve the same effects and it needs increasing use in order to achieve the same levels of pleasure originally experienced (National Institute on Drug Abuse [NIDA], 2008).

The psychological effects of cocaine depend both on the amount consumed and on the route and modality of administration (Braglia et al., 2004): these effects consist mainly of sensations of euphoria, increased libido, reduction of hunger and thirst, and in the impression of increased perceptual abilities, but they may also generate panic attacks, mood disorders, paranoid ideation and induction of psychotic states with auditory, visual and tactile hallucinations (Braglia et al., 2004). Among the various routes of administration, the intravenous injection and the cocaine smoke are those causing a more rapid and intense 
action, while sniffing cocaine determines longer lasting effects, up to 30 minutes versus the 10 minutes of the smoke (NIDA, 2008).

Based on currently available data, cocaine addiction is a complex phenomenon in which various factors interact; there are those that are dependent on the central nervous system and therefore biological and those that are related to a certain lifestyle that from the point of view of the cocaine addict would encourage new opportunities for social meetings, sexual gratification and friendship (Rigliano, 2004).

\section{Main therapeutic intervention protocols}

Despite the considerable and ever increasing spread of cocaine, therapeutic intervention protocols that exist today in Europe are unfortunately still being tested and often result from treatment of other forms of addiction, such as heroin (EMCDDA, 2007a).

The pharmacological approach intervenes with the neurobiological systems involved in reinforcement and the long-term effects of drugs, thereby reducing the symptoms of abstinence. Most recently, some vaccines have also been developed based on the principle of using the properties of the immune system to counteract cocaine effects, preventing it from reaching the brain (Pirona \& Hendrich, 2009).

The pharmacological approach, although representing a significant step forward in the care and treatment of cocaine dependence, has not proven sufficient to effectively treat cocaine addiction. The reason for this is that cocaine addicts continue to remember the pleasurable effects and states of arousal produced by the substance, and the attempt to reduce any preexisting states of discomfort through the use of the psychoactive substance. Therefore, it is essential to integrate the pharmacological approach into a psychosocial and psychological treatment.

Among the various psychological orientations that have been proposed, those which have demonstrated a good level of effectiveness are as follows:

\subsection{Cognitive Behavioural Therapy}

Cognitive Behavioural Therapy (CBT) (Carroll, 1998) that treats cocaine addiction as a problematic behaviour depending on cognitive and environmental factors. Treatment is usually delivered on an outpatient basis and it lasts from 12 to 16 sessions, usually over 12 weeks. An individual format is preferred, because it makes possible to fit the treatment to the needs of each patient.

According to $\mathrm{CBT}$, the learning processes are important factors for the development and the maintenance of cocaine use, but the same processes may be useful for helping the patient stop his drug use. So, CBT tries to assist the patient to recognize the situations in which he most probably takes cocaine, to avoid these circumstances if it is possible and to manage the difficulties and the problematic behaviours related to the cocaine use. CBT has two important components:

- functional analysis, that is, the identification of the patient's thoughts, feelings and circumstances before and after cocaine use. The functional analysis is helpful to assess the factors, or high-risk situations, that are likely to lead to cocaine consumption and it can gives insights into some of the causes of this use; 
- skills training, aimed at unlearning the patient's habits associated with cocaine use and learning healthier skills and habits. At the beginning the skill training focuses on the practical and mental abilities which are useful to stop cocaine use. Then, the training is extended to other possible problems with which the patient may have difficulty facing (Carroll, 1998).

So, CBT encourages subjects to assume alternative behaviours than those associated with substance use (EMCDDA, 2007a).

\subsection{Contingency Management Therapy}

Contingency Management Therapy (Petry, 2002), based upon the principles of behaviour modification. This consists of providing positive reinforcement (in the form of clinic privileges, vouchers or payment) when the patient achieves given behaviours or treatment goals. In particular, for cocaine users this reinforcement is related to the urine tests carried out periodically (Higgins et al., 2000).

This therapy has four main values:

- defining a target behaviour, that is, what outcome the patient has to achieve. For example, drug abstinence and undertaking clinic and social activities related to a drug-free lifestyle;

- regular monitoring of target behaviour that has to be unequivocally assessed (for example, regular urine analysis would be undertaken to verify the patient's abstinence);

- reward contingent on achievement of target behaviour: at pre-established levels and frequencies, rewards are given to or retained by the patient depending on whether or not the target behaviours are achieved;

- reinforcement by brief counselling to reinforce the positive effects of the rewards (Weaver et al., 2007).

\subsection{The Motivational Interview}

The Motivational Interview (MI) (Miller \& Rollnick, 2002) approach is a client-centred, directive method aimed at understanding the motives the patients have for addressing their substance use problems, to gather the clinical information needed to plan their care and to build and reinforce their readiness for change. The MI approach consists of short-term intervention to help the person in the changing process towards a healthier lifestyle through the resolution of ambivalence, that is, the tendency to provide opposite emotional responses to cocaine.

According to the MI, the patient can be in one of the following four stages of change:

- $\quad$ pre-contemplation stage, in which the patient does not want to change his behaviour;

- contemplation stage, when the patient would like to change, but he does not know how to do it;

- preparation stage, in which the person shows explicitly the intention to change;

- action stage, in which the patient realizes practical changes to feel better (Di Clemente \& Velasquez, 2002).

\subsection{Modified Dynamic Group Therapy}

Modified Dynamic Group Therapy (MDGT) (Khantzian et al., 1990) aims to solve the problems of low self-esteem that lead the subjects to consume the substance. According to 
this theory, low self-esteem produces a "psychological vulnerability" which can predispose a person to drug use and decrease impulse control. The purpose of MDGT consists of helping patients become aware of their psychological vulnerability. This approach has four main therapeutic focuses:

- developing a better affective tolerance;

- $\quad$ improving self-esteem;

- improve interpersonal relationships;

- development of appropriate strategies of "self-care".

MDGT lasts about 6 months and has 3 main stages:

- during the first stage therapy consists of encouraging patients to address their vulnerability through better confidence resulting from the support of other members of the therapy and mutual listening;

- $\quad$ in the middle stage the attention is on members' attachment to the group, taken as a whole;

- in the last stage the older members take on the role of "co-therapists" and explain aspects of MDGT to new members.

So, the MDGT intervenes not only on drug use, but also in the self and on the relationship between some personality aspects and problems that can lead to relapse (Khantzian et al., 1990).

\section{The interactional approach}

The Interactional Approach (IA) is a type of psychological intervention that includes specific therapeutic techniques and procedures for the treatment of cocaine addiction.

Attempting to solve the problem of cocaine addiction, our research group has developed a short-term psychotherapeutic model, directed to increase the patient's interpersonal and communicative skills, to improve emotional control and the use of meta-cognitive resources, to adopt a healthy lifestyle, leading eventually to reduced risk of relapse. The proposed outpatient treatment has led to good results both in terms of effectiveness and efficiency (Leonardi et al., 2006, 2009; Leonardi \& Velicogna, 2009).

At the basis of the psychological intervention there are studies on the processes of persuasive communication (Erickson et al., 1976; Erickson \& Rossi, 1981), as well as theoretical models derived from constructivism (von Foerster, 1982; von Glasersfeld, 1984), the interactional approach (Jackson, 1961, 1965; Fisch et al., 1982; Watzlawick et al. 1967, 1974, 1984, 1997) and those derived from action research (Lewin, 1946).

Constructivism is a theoretical approach that challenges the idea that knowledge can be "objective", arguing that each man builds his own reality through cognition, sensory perception and communication processes. What the person sees and knows is a construction based on his own experiences. Therefore, from a psychological point of view it becomes essential to try to understand the meaning that individuals attribute to their experiences, how they organize their knowledge and the expectations they have about what will happen to them. Other authors who have contributed to develop this approach were Maturana and Varela (1980), who studied the way in which living systems are regulated and organized in their environment. 
The interactional model is applied to relational aspects and it is based on the concept that psychological disorders depend on the interaction between the subject and his own perception of reality: the aim of the therapy is to facilitate the change through appropriate strategies, so that individuals can look at their problems in a different way and take the best solutions.

It often happens that just the attempted solutions ${ }^{1}$, implemented by the person, contribute to complicate the problem inadvertently, while with appropriate strategies it becomes possible to change the patient's perceptive-reactive system, as well as his perspectives which are too rigid. The perceptive-reactive system is defined as the way a person constructs the three fundamental relationships: with himself, the others and the world. Thus, by intervening it is possible to change the processes of attribution of meaning to things over the perception of the problem (Nardone \& Watzlawick, 1990).

In accordance with Franz Alexander (Alexander \& French, 1946), the change is due to the corrective emotional experience that helps to modify initially set perceptions and in doing so engaging a virtuous process of learning new skills and competencies in the social sphere. Therefore, the scope of the interactional and constructivist therapy is to get the patient to change his perceptive-reactive system, through the experimentation with new and different strategies.

With regard to the interactional aspects, injunctive and evocative language is also really important: its aim is not to describe the surrounding reality, but to prescribe certain behaviours within a therapeutic relationship full of suggestion. Such injunctions can be very useful to interrupt the patient's dysfunctional patterns. The injunctive and evocative language is used to persuade the other to engage in specific tasks. Through the execution of such tasks the patient may perceive reality in a different way (Watzlawick, 1978).

Finally, our methodology of psychological treatment takes into consideration some aspects such as the neurological functional difference between the two hemispheres of the human brain. The left hemisphere uses a logical-analytical coding system and it specializes in the perception and in language, while the right one is involved in non-linguistic tasks such as recognition of their own and others' emotions or in activities that involve analogical processing such as the perception of images, configurations and contexts in their overview (Gazzaniga, 1972). The study of different functional specializations has been possible thanks to research on patients suffering from epilepsy and who had the corpus callosum surgically sectioned, a brain structure that represents the most important area linking the two hemispheres. Those studies revealed that the two hemispheres work in close synergy with each other, although responding to specific stimuli to their functional area, and that they are also highly integrated and complementary (Sperry, 1968).

According to Watzlawick (1978), a specific language is able to communicate and influence each of the two hemispheres, in order to activate one at the expense of the other: for example, evocative language and hypnosis without trance ${ }^{2}$ (Erickson et al., 1976) are communicative modalities that can influence the right hemisphere. The purpose of these

\footnotetext{
${ }^{1}$ The attempted solutions are actions that a person does to try to solve his problem. If they do not lead to the resolution of the problem and if repeated, these solutions further complicate the situation preventing the change (Watzlawick et al., 1974). From the perspective of the therapist, the attempted solutions function as reducing complexity in the assessment of the clinical case examined.

2 Without using formal hypnosis, Milton Erickson (Erickson et al., 1976) states that it is possible to realize a communicative exchange characterized by persuasion, control of attention and suggestion, which is able to bypass resistance to change.
} 
communicative approaches consists of evoking certain images in the patient, as with the storytelling of metaphors, aphorisms and anecdotes. As a point of fact, these communicative modalities serve to bypass the normal resistance to change and provide easier access to unconscious psychological resources (Erickson et al., 1976).

In the therapeutic relationship, the use of suggestion, as well as the evocation of images, allows patients to gradually change their behaviours.

The experience "on their skin" of such behaviours allows the persons to realize that new ways of handling their problems are possible. The cognitive restructuring of these new experiences contributes to maintaining over time the modifications that have progressively occurred.

\section{The five phases of the interactional model for the treatment of cocaine addiction}

Our model is applied to both individual and group therapy. It can be divided into five phases of intervention that are interconnected with many levels of communication: each of these five phases is characterized by specific objectives and the achievement of each one allows access to the next level (Leonardi et al. 2006, 2009; Leonardi \& Velicogna, 2009).

\subsection{Evaluation-intervention}

The purpose of the first phase is to collect useful information to explain how cocaine addiction has been established, to evaluate the level of motivation and to begin simultaneously the intervention aimed at changing.

Unlike what happens with other therapeutic approaches, such as Cognitive Behavioural Therapy (CBT) (Carroll, 1998), which uses more linear intervention strategies, our model consists of a sequence of self-corrective operations aimed at progressively increasing the effectiveness of care, which is accompanied by a circular type system of interaction with the patient. This happens from the first stage, in which there is no distinction between diagnosis and intervention. This distinction characterizes the traditional approach to the problem of cocaine addiction, where the time of diagnosis is considered free from possible communication influences.

During this initial phase, the therapist:

- $\quad$ investigates and assesses the overall situation;

- recalls situations associated with cocaine use;

- plans the most effective communication strategies to change the way the patient relates to the substance.

After collecting information on a person's life, the therapist identifies those elements that may have influenced the development of cocaine dependence (anamnesis). In parallel, he also seeks to assess the patient's level of motivation to change, which generally falls into one of the following categories:

- $\quad$ the person is motivated to seek help;

- the person is slightly motivated to seek help and forced into treatment by the family; 
- the person is not motivated to change at all.

The elements of this scheme are additional to the already described usual resistance to change of the dysfunctional systems (Haley, 1963; Nardone, \& Watzlawick, 1990).

The start time of problematic cocaine use and whether it coincided with a traumatic event should be assessed carefully (Leonardi \& Velicogna, 2009).

It often happens that people who have occasionally used cocaine for fun or curiosity, increase their use considerably as a result of difficult situations that need to be addressed (such as bereavements, emotional loss, work problems, etc.), until the onset of a real physical and psychological dependence. Therefore, the therapist has to not only take care of the drug addiction behaviour, but he must attend also to the potential event that made things worse. Finding the possible reason that has contributed to the subsequent loss of control by the cocaine addict allows him to address the "real" problem that caused the suffering that he has tried to quell using cocaine (Leonardi \& Velicogna, 2009).

Another important factor to take into consideration concerns modes of taking cocaine (which can be sniffed, smoked or injected into veins), because the therapeutic intervention must be calibrated depending on the method of intake of the substance. For example, in the case of cocaine injected into veins, in our experience we are often in the presence of a former heroin consumer that, maybe after years of abstinence, has decided to switch to cocaine and this must be taken into account in the psychological intervention. In the case of smoked and sniffed cocaine the sensory, perceptive and imagination techniques change, although the process of therapeutic intervention is similar.

During this first phase (see Table 1), the therapist adopts a style of communication aimed at increasing the level of the patient's motivation to overcome his natural resistance to change: through questions that explore the problem, we aim to change both the perceptions and reactions to the substance.

\begin{tabular}{|c|c|}
\hline First phase of treatment & First level of therapeutic communication \\
\hline $\begin{array}{ll}\text { - } & \text { History and evaluation of general areas } \\
\text { - } & \text { Motivational levels } \\
\text { - } & \text { Outset } \\
\text { - } & \text { Modensity } \\
\text { - } & \text { Frequency }\end{array}$ & $\begin{array}{l}\text { - } \quad \text { Persuasive communication } \\
\text { - } \quad \text { Hypnosis without trance }\end{array}$ \\
\hline
\end{tabular}

Table 1. The evaluation-intervention.

For example, if a patient has just conjured up feelings of isolation and loneliness in relation to cocaine use, the therapist could explain this perception by means of a metaphor, comparing the patient to a person who is locked in by himself inside a cold and dark cell. This image evokes a painful sensation, but, at the same time, it produces a very refined restructuring because if a person has been able to enclose himself within a cell, he is also able to open it and to get out. As stated above, according to constructivist theory, the person may know and interact with the world around him through his own actions. Thus, an "objective" knowledge of reality is not possible, it depends upon the observer's point of view. But often the person is not aware of that building process. Rather, for that person 
knowledge has the value of "objective" truth and strongly influences his thoughts and actions (Nardone \& Watzlawick, 1990).

On the one hand the interactional intervention works on the problem, on the other it has the aim of helping the patient to gradually build a different reality (De Shazer, 1985).

\subsubsection{First clinical interviews}

The first clinical interviews with cocaine users are crucial in order to explore the ways to develop the treatment. They serve to gather a preliminary knowledge of the individual and to lay the groundwork for increasing motivation to change: the patient describes in detail his problematic situation, which is compounded by drug-induced automatisms and compulsions.

Generally, people who seek psychological help for a problem of abuse and cocaine addiction have three levels of complexity that prevent the change:

- at the first level there is the inevitable resistance that occurs in this clinical setting, (Mascetti \& Strepparola, 2006);

- $\quad$ at the second level lie the neurobiological modifications induced by cocaine use that render the brain less susceptible to changes (Shaham \& Hope, 2005a; Edwards \& Koob, 2010);

- finally, at the third level there is a lack of motivation of those who have been forced by family to undergo treatment.

Because of these difficulties, which are added to by the specific problems due to cocaine use, in this preliminary stage the use of the persuasive communication mode reaches noteworthy levels. In fact, by only "capturing" the attention of the patient it is possible to change his behaviour first and then, subsequently, also his perceptive-reactive system.

At this stage, the first question should be: "What is the problem?". According to our model, this simple question already contains an initial restructuring message, since the patient is not considered as a chronically ill patient, but he is treated as an individual who has a problem which can still be given a solution.

This is also the time to try to understand how the perceptive-reactive system works in relation to the problem of drug addiction. On the basis of our clinical experience gained over the years, we have found that cocaine users usually act like sensation seekers (Zuckerman, 1979), that is as people who actively and constantly seek strong pleasurable experiences.

Often, the first cocaine consumption happens randomly in a fun and entertaining context, such as in a club with friends. After a number of takings, which may vary from individual to individual, there is the loss of control leading to the emergence of a vicious circle which tends only to worsen (Serpelloni \& Bertoncelli, 2006; Pavarin \& Dionigi, 2009).

It is of the utmost importance to ask the patient to relive those first experiences of use: this re-enactment aims to make the patient conscious of the act of taking cocaine so that it ceases to be a mainly automatic process.

Generally, at the first interview the individual states that, after an initial phase characterized by extremely pleasurable sensations, side and opposite effects occurred (paradox effect). At 
this stage the therapist adopts a communication style characterized by suggestion and persuasion, emphasizing that cocaine has caused unpleasant effects which are opposite to those originally experienced and it is now those unpleasant effects that the patient wants to stop as soon as possible (Leonardi \& Velicogna, 2009). To do that the therapist may use an analogy such as that of the cage, already mentioned above, to get the best view of the situation and to evoke the unpleasant feelings associated with cocaine use. The therapist ends the sentence with a post-hypnotic message: "The more you use it, the more you feel sick and the more you feel sick, the more you would like to free yourself of it."

The next step is to survey the attempted solutions that the patient uses to address cocaine addiction. Generally, there are three:

- $\quad$ appeal to the patient's willpower to resist the temptation to give in to drug use;

- $\quad$ avoid risk situations;

- try to not think about the substance.

In order to achieve the goal of getting out of vicious circles established by the failed attempts to solve problems, the questions asked by the therapist act as keys that unlock the ability to change. For example, at this stage a question feature is: "Now that you have decided to change your ways by coming here, what would you do to implement this?". This question prompts the person to feel as if he is actually changing and he is trying hard to do it, thus creating a prophecy that has a sensible hope of self-fulfilment ${ }^{3}$.

Another category of questions is the one that puts the illusion of creating alternatives between two opposing choices. An example of this sequence of funnel-shaped questions could be the following: "Do you take more cocaine when you are with other persons or when you are alone?" If the answer is "alone", the therapist continues asking if this taking is usually done at home or outside. In this way we proceed with other questions of the same type, until the therapist summarizes all the collected information into a single sentence which aims to make the patient relive the intense feeling of loneliness that the drug causes every time, thus using the patient's arguments.

Change can be induced by other tools, such as metaphors, analogies and citations, because they have the advantage over the hedges of the analytical processes (Watzlawick, 1980), as well as having a strong educational and evocative component.

Towards the end of the first session, the therapist applies a therapeutic double bind ${ }^{4}$ (Bateson et al., 1956), thus constraining the individual to be even more motivated to change. An example of a double bind is when the therapist at the end of the interview states that "usually the treatment works, but I don't know if it is so in your case. We'll see...". If the patient wants treatment to work, here he must commit to belonging to that category of people for whom the treatment was successful.

${ }^{3}$ The self-fulfilling prophecy is a prediction that, because it has been formulated, sooner or later it will be fulfilled. People who are convinced that a certain event will happen in the future, in the short or medium-term, tend to alter their behaviour in a way that ends in causing the events that they had expected (Watlawick et al., 1967).

${ }^{4}$ The concept of the therapeutic double bind was formulated by Bateson to describe a contradiction at the level of communication, both verbal and non-verbal. 
Finally, we give the prescriptions ${ }^{5}$, which can be direct or indirect behavioural injunctions formulated by means of a strongly suggestive language, so that the patient performs the task assigned between sessions. The behavioural prescriptions are intended to unhinge the attempted solutions used until then.

\subsubsection{Psychological assessment}

Although the interactional model is not planned to frame people by the diagnosis, however, our team has used a series of psychological assessment instruments to obtain statistically valid measures for research purposes.

The assessment procedure aims to evaluate personality elements and those related to selfesteem, cognitive processes and social skills. Therefore, diagnostic tools used in the research project investigate the relationship between behaviour, personality factors and attitudes.

The survey instruments are:

- the Eysenck Personality Questionnaire Revised Short Form (EPQ-RS) (Eysenck et al., 1985), which measures some personality traits like introversion and extroversion;

- the Parental Bonding Instrument (PBI) (Parker et al., 1979), which provides a reliable and valid evaluation about the relationship with both parents, especially with regard to the level of care received and the feelings of security;

- $\quad$ the Basic Self-Esteem Scale (SE-BASIC) (Forsman et al., 2003), which consists of a rating scale of self-esteem in adulthood, seen as a stable personality trait over time and whose score is independent of the skills and feedback received from others.

- other indices of cognitive and behavioural assessment that have been extrapolated during the psychological observation of patients, with particular reference to verbal and non-verbal communication factors.

\subsection{Motivational intervention}

In the second phase we address the problem of dependence, encouraging the patient to speak freely about the difficulties encountered in the relational and family field, which may have favoured the use of cocaine. This work is important not only because it allows defining the possible critical areas for the person, but also because it helps to shift attention from the main problem, cocaine, and it helps to decrease obsessive ideation about the dependence on the substance.

In fact, two seemingly contradictory phenomena can be detected in the problem of cocaine addiction: obsessive ideation about the substance and mental dissociation that occurs during the use. To counter these two aspects of the problem, patients should be stimulated in sensory, perceptual and cognitive awareness (Main, 1991; Bara et al., 2005; Leonardi \& Velicogna, 2009; Belin et al., 2011) of the occurrence of the abuse of cocaine.

${ }^{5}$ Direct prescriptions are clear instructions to carry out specific actions. They are aimed at the resolution of the problem or at reaching one of a series of goals on the road to change. Indirect prescriptions are behavioural injunctions whose real objectives are hidden. The therapist prescribes an action that will produce a different result from the one that was seemingly being specified (Nardone \& Watzlawick, 1990). 
To effectively achieve the treatment objectives, it is necessary to establish a relationship with the patient geared to the understanding of the problem and to mutual cooperation. The therapist must try to convey the message to the patient that he is not judging him by the fact of being dependent on a substance. In addition, rather than commiserate or treat him as an incompetent, the therapist encourages the patient to take responsibility and develop better decision-making capacity. Depending on different situations, the relationship with the patient can take directive or non-directive aspects.

At this stage (see Table 2), we use specific intervention techniques to re-enact sensations and perceptions induced by cocaine on the imaginative level, thus increasing the patient's capacity to recall the context in which the drug abuse developed and to prevent a possible relapse.

\begin{tabular}{|ll|ll|}
\hline & \multicolumn{2}{|c|}{ Second phase of treatment } & \multicolumn{2}{l|}{ Second level of therapeutic communication } \\
\hline$\bullet$ & Further evaluation-intervention & $\bullet$ & Therapeutic capture \\
$\bullet$ & Intervention on the use of cocaine & $\bullet$ & Sensory and perceptual intervention \\
\hline
\end{tabular}

Table 2. The motivational intervention.

A special technique was developed called the transformational re-enactment technique (Leonardi \& Velicogna, 2009). This re-enactment is much more intense than just simple memory recalling, because it becomes possible to highlight the unpleasant moments connected with the use of the substance.

Here now we provide an example of a case study to explain how this technique is structured, based on our previous publication (Leonardi \& Velicogna, 2009, p. 48):

(...) Gaetano, 35 years, has had a problem of cocaine addiction for about five years. He is a building contractor by profession, married and childless. In the past, he had abused heroin from the age of fifteen, but he was able to solve this problem after a period of one year in a drug rehabilitation centre. Abstinent for a long time, then he begins to take cocaine underestimating the risks and he loses control very quickly.

During the motivational phase, the therapist applies the transformational re-enactment technique, asking the patient to recall a typical situation of cocaine abuse. Despite encountering some difficulties in the initial stage, the patient gradually achieves very satisfactory results: in fact, Gaetano claims to perceive a certain aversion in reviewing that situation, underlining that he had never thought previously about the specific moment of cocaine use.

Continuing with the treatment, the therapist puts a new element in, representative configuration of use, which takes advantage of the discomfort the patient feels in "seeing" himself during the action of using cocaine (principle of use, Erickson et al., 1976). In fact, the patient tries to live again the moments immediately preceding the situation of abuse, during cocaine use and then after, as if he was reviewing them in front of a mirror. The effect obtained is very strong, because it completely changes the perception that the person had so far: whereas before the use was associated only with pleasure, now painful and negative feelings appear. Taking advantage of the difficulty of see himself, the therapist assists in leading to a greater fear in the patient, through the dual action to see the scene and to be able to review his actions. 
The next step was to create an alternative sequence in which Gaetano was able to avoid the situation of abuse, reviewing with satisfaction: him reducing the use until complete cessation and then focusing his attention on relationship problems and the lack of selfesteem that had led him to cocaine addiction.

Using the transformational re-enactment technique, the therapist achieves three different objectives:

- to avoid automatisms. This technique allows the patient to review, at sensory and perceptual level, three fundamental aspects of cocaine consumption: what happens before, during and after use. It has, also, the prescription of the symptom ${ }^{6}$ function, because it forces the patient to re-think in detail something that until now escaped control: the dependence;

- to insert in the patient's memory of cocaine use minimal elements with an aversive content against the substance. Thus, the patient lives painful and unpleasant sensations at perceptual level, every time he thinks about the substance;

- the modification of the patient's mental patterns into more adaptive ones, so that he can imagine himself doing affirmative actions for his mental and physical health.

Patients treated with this technique have gradually reduced cocaine use, often eventually complete cessation of using the drug, so that in a short time they were able to focus on their relationship problems and lack of self-esteem (Leonardi \& Velicogna, 2009).

\subsection{Development and consolidation.}

The third stage is used to consolidate the results achieved in the previous two phases, proceeding in this way to restructure the cognitive level, in terms of less rigid alternatives in the perception of the reality.

In this phase, which may occur during group or in individual sessions, we try to ensure that the patient thinks of new skills acquired through the therapeutic treatment. The course within a group has some advantages in terms of learning, because the person interacts with other individuals who share similar problems. Many circular exchanges occur in a group and they can improve the patient's capacity to communicate with himself, the others and the world. So, the thought moves from the main problem: cocaine. In this way the mobilization of meta-cognitive resources helps to control the impulsivity that is typical of drug addicts and has been shown to contribute to compulsivity (Belin et al., 2008; Dalley et al., 2011). The ability of meta-communication (Sluzki, 1966; Watzlawick et al., 1967; Bateson, 1972; Belin et al., 2011) about cocaine addiction also helps the individual to reflect on interactions with his social environment.

The development and consolidation phase (see Table 3) serves also to decrease the risk of relapse that may occur after several months or even years after cessation of use. Indeed, the prolonged use of cocaine produces changes at the neurobiological level (Huang et al., 2009; Dobi et al., 2011, for review see Belin et al., 2009), which likely involves the formation of a

\footnotetext{
6 The prescription of the symptom is a type of paradoxical prescription. The patient has to perform voluntarily actions that were previously involuntary and uncontrollable, and that he had always tried to avoid. The voluntary performance of the symptom eliminates it, as it is no longer spontaneous and uncontrollable (Nardone \& Watzlawick, 1990).
} 
long-term memory trace (Lee \& Dong, 2011) about the pleasurable effects caused by cocaine, even after a single exposure (Ungless et al., 2001). Thus, working on meta-cognition it becomes possible to act on the mechanisms of impulsivity that may promote relapse in cocaine addiction.

\begin{tabular}{|c|c|}
\hline Third phase of treatment & Third level of therapeutic communication \\
\hline $\begin{array}{ll} & \text { Therapy admission } \\
\text { - } & \text { The seven therapeutic topics }\end{array}$ & $\begin{array}{ll}- & \text { Increased collaboration } \\
\text { - } & \text { Decrease in the evocative language }\end{array}$ \\
\hline
\end{tabular}

Table 3. Development and consolidation.

\subsubsection{The seven learning topics}

The intervention we propose acts on the specific problem of addiction and on the possible situations that led to its appearance. For this reason, we use seven learning topics that are connected to each other and relate to many psychological areas. Considering and confronting each other about these topics we invite the patients to act in a more constructive way (O'Connell \& Palmer, 2003).

\subsubsection{Choosing a healthy lifestyle}

The difficulties that a person normally encounters in the management of his lifestyle can be exacerbated by cocaine addiction (Serpelloni \& Bertoncelli, 2006). At this phase, the focus of the therapy is on the possible choices which the patient can make to improve his own life. The purpose of this topic is to increase the ability to organize and direct daily activities towards healthier life choices. Adherence to more balanced rules of life, such as living by time schedules, eating a healthy diet and doing sport, allows individuals to build a healthier lifestyle.

\subsubsection{Avoidance of relapses}

Through group discussion assisted by the facilitator, we focus on the reasons that led to the patient using cocaine in the past. These may be different, such as difficulties in managing specific emotional states, the problems related to significant emotional relationships or risk underestimation in certain circumstances.

Awareness of the factors that can lead to relapse may be increased through reflection on the choices made, on automatic thoughts 7 and on emotional experiences occurring in certain circumstances. In accordance with the principle of use, we try to exploit even possible relapses in a positive way: instead of judging them as failures, they are redefined as opportunities to move on with greater and renewed commitment. According to Milton Erickson (Erickson et al., 1976), the principle of use is based on identifying the patient's available resources, on the understanding of his belief system, on connecting the resources to deal with the problem and on conveying confidence to the patient about the fact that the present problems will soon be overcome.

\footnotetext{
7 Automatic thoughts are ideas and unexpected images that the patient has when their beliefs related to addiction are activated. These thoughts may act to trigger and increase drug withdrawal (Newman \& Ratto, 1999). Through repeated observations, the patient is able to consider objectively their automatic thoughts and recognize their possible unreliable and non-adaptive features. Beck (1975) calls this process distancing.
} 


\subsubsection{Increasing social skills}

Cocaine tends to alter the state of consciousness, distorting the perception and, therefore, it worsens the person's ability to significantly relate to others. The experience of being part of a group is a powerful tool by which he constructs a network of shared meanings with other members. The facilitator helps group members to focus on the present moment, inviting them to feel the emotions that they are experiencing during the dialogue with others.

\subsubsection{Development of communication and meta-communication skills}

The communication can never be separated from the interactional aspects: the person learns to communicate through the discussions that take place in the group, drawing on the resources of the verbal and non-verbal sphere. The development of communication skills helps to contrast feelings of isolation that often accompany the experience of cocaine addiction.

\subsubsection{Increasing meta-cognitive resources}

Meta-cognition is the ability to reflect on your thought processes, because it is assumed that an increase of this ability may encourage the person to make global changes in his lifestyle and in the management of feelings evoked by the use of cocaine. The group facilitator invites the members to meta-communicate and reflect on their and others' thinking, in order to stimulate greater awareness in emotion management.

\subsubsection{A more balanced emotion management}

Group members are instructed to recognize their own emotions and those of others: in other words, everyone is invited to wonder what he feels and what the others feel. To do this, the group members are invited to observe their sensations here and now and to realize the emotions of others. The same process can be referred also to remember particular events, such as the cocaine use situation. Observation and acceptance of their emotional states play important roles in the recognition of unpleasant emotions associated with the use of the substance.

\subsubsection{Increasing problem solving skills}

Increasing the capacity to solve problems effectively is obtained by assigning to the group members problem solving exercises to stimulate learning more appropriate strategies. This capacity can also improve the perceived sense of self-efficacy and thus the level of selfesteem of the person.

The self-efficacy refers to all the beliefs the person has about their ability to organize and execute the necessary actions to achieve their goals (Bandura, 1997).

\subsection{Gradual release}

Once you have completed the phase of development and consolidation, the next step requires the patient to acquire greater autonomy and self-confidence. The therapeutic session takes place during this phase with a collaborative attitude, in order to monitor any signs which could have anticipated the risk of relapse in cocaine addiction. At this stage, the patient has gained a greater autonomy and confidence in his ability to continue alone down the road of change. In this regard, it is interesting to focus on the concept of deutero- 
learning, introduced by Bateson (1972), to indicate the learning level higher than that of the basic stimulus-response scheme: briefly, it describes the process by which an individual "learns to learn".

This step is essential to encourage the patient to develop a greater degree of autonomy (see Table 4), as well as a greater sense of security, such as he becomes able to deal with various difficult situations.

\begin{tabular}{|c|c|}
\hline Fourth phase of treatment & Fourth level of therapeutic communication \\
\hline $\begin{array}{l}\text { - Increasing autonomy } \\
\text { - Increased complexity of the arguments } \\
\text { of the group } \\
\text { Deutero-learning }\end{array}$ & $\begin{array}{l}\text { - } \\
\text { Pemonstration-rational language } \\
\text { intervention }\end{array}$ \\
\hline
\end{tabular}

Table 4. Gradual release.

During this phase, the therapist also aims to improve the quality of inner dialogue, for example, through a specific training technique called inner conversation (Leonardi \& Velicogna, 2009), whereby the patient imagines himself thinking as speaking aloud, focusing so that his linguistic performance is as correct as possible. This exercise leads to a progressive increase in reflective ability (self-regulation of thought) with a corresponding decrease in impulsivity, which is one of the reasons of possible relapse in cocaine use, as demonstrated by preclinical studies (Economidou et al., 2009).

\subsection{Follow-up}

After treatment, the phase of periodic review of results begins and it is realized by monitoring urine tests and follow-up interviews. This is the time (see Table 5) to understand whether or not the therapy has reached its objectives: the patient should become more cooperative towards the therapist, as well as more inclined to discuss any other issues that have occurred in other areas of his life.

In order to avoid possible relapses, at this stage the therapist also uses training techniques and imaginative simulation procedures, similar to the transformational re-enactment technique described above.

\begin{tabular}{|c|c|}
\hline Fifth phase of treatment & Fifth level of therapeutic communication \\
\hline $\begin{array}{l}\text { Verification, development and } \\
\text { consolidation of achievements }\end{array}$ & $\bullet \begin{array}{l}\text { Increased collaboration } \\
\text { Collaborative language }\end{array}$ \\
\hline
\end{tabular}

Table 5. Follow-up.

\section{Evaluation of the effectiveness and efficiency of treatment}

Cocaine addiction is a highly complex field of study, in which communicative, interpersonal and neurobiological processes act. In order to collect data about the effectiveness (that means to cease cocaine use) and efficiency (to reach this goal as soon as possible) of the interactional approach, our research group has used both quantitative tools, such as urinary tests, and qualitative tools, such as self-evaluation questionnaires completed by the patients directly. 
Through these evaluations indexes, given before, during and after treatment, we think it is possible to obtain a reliable evaluation of the treatment outcome.

Data collected are used:

- to assess whether treatment produces concrete results and if it responds adequately to the initial expectations;

- to identify which aspects of the treatment are valid and which ones are ineffective and, therefore, modifiable;

- to improve further those treatment components that have shown to be effective.

One of the rules of scientific method is to never be satisfied with the results achieved, because in another context or with other patients the same results achieved in the past may not be obtained. So we need a constant monitoring of these activities, in order to modify certain aspects of the psychological intervention, if necessary.

In a previous article (Leonardi et al., 2006), we underlined the importance of this circular deepening principle which derives from Lewin's Action Research model (1946). According to this model, the research and intervention phases are interconnected and constantly changing thanks to a feedback mechanism. After theoretically defining the working hypotheses, the real finding phase, during which data are collected, follows. Through the analysis of these data it becomes possible to effectively coordinate the intervention. The evaluation of achievements generates new working hypotheses, thus determining the beginning of a circular process whereby it becomes possible to make corrections and changes to the treatment itself.

This cycle also allows us to adjust the treatment to very different realities compared to the initial sample which has been processed. As Trombetta and Rosiello (2000) claimed, the circularity of this process is characterized by a collection of new material to be analysed, which is then used in constructing and implementing new strategies and action plans.

The principle of circularity just described is consistent with systemic theory (von Bertanlaffy, 1971), which underlines the importance of feedback mechanisms that act through the different phases: in our case, these feedback processes concern the continuous analysis of clinical individual and group interviews, as well as observation of results achieved (urinary tests, remission of symptoms and change in behavioural style).

Over the years, this circular process has meant continuous improvements to the treatment protocol, thus increasing the final effectiveness.

The research process can be divided into three macro areas:

- observation of individual and group interviews;

- quantitative and qualitative monitoring of the results obtained, and the administration of cognitive and personality tests;

- theoretical study in the field of general psychology and drug addiction.

The evaluation of therapeutic work mainly consists of studying the interviews or the group meetings carried out, with particular reference to the interactional aspects which occur between the therapist and the patient. 
As noted elsewhere (Leonardi et al., 2006), monitoring of the clinical situation through periodic urine tests represents an element of fundamental importance and is the primary tool to verify the abstinence from cocaine and thus, indirectly, to obtain an objective evaluation index on the effectiveness of treatment.

According to our intervention protocol, urine tests should be carried out twice a week during treatment. These data provide an objective parameter for achieving and maintaining abstinence from cocaine, and they are also used to detect the possible occurrence of relapses. The statistical analysis of urine test results also allows the detection of the presence of some critical periods during the course of treatment, when abstinence from the drug is relatively more likely to be established (see Leonardi et al., 2006, for more details).

To monitor the validity of the therapy we also use some subjective evaluation indices that refer to how the patients views the therapeutic activity, the skills that they believe they have acquired during the treatment and the personal areas where they would require further therapeutic intervention. These evaluations are obtained through semi-structured interviews.

Finally, the study of general psychology and drug addiction literature has allowed expanding the existing knowledge, implementing it with new ways to observe and act on the person. The updating of bibliographic material is designed to deepen knowledge about the neurological, cognitive and social aspects related to the phenomenon of cocaine addiction.

\section{Conclusions}

Solving the problem of cocaine addiction presents considerable difficulties because of frequent relapses in the use of the substance. For this reason, a gradual change of subjective models for the construction of reality should also be combined with the psychological change, which begins to develop from the first session.

The interactional model has allowed us to reach good levels of effectiveness and efficiency of treatment. For example, as reported in Leonardi et al. (2006), in a group of 22 subjects who finished the treatment successfully, $73 \%$ resulted in abstinence from cocaine after 12 weeks. A 12 week outpatient study of Carroll et al. (1991), comparing the effectiveness of CBT with Interpersonal Psychotherapy or IPT (Klerman et al., 1984), reported that in a group of 42 subjects, $57 \%$ of the patients assigned to CBT and $33 \%$ of those assigned to IPT attained three or more continuous weeks of abstinence.

Our results (see Leonardi et al., 2009, for more details) were achieved by continuous research and correction of what was not fully satisfactory for the purpose of the therapy. On the basis of the results and data collected over time, we have developed a specific protocol for dealing with the problem of cocaine addiction, characterized by the following principle: try constantly to adapt the treatment to changes occurring during the therapeutic work.

\section{References}

Alexander, F. \& French, T.M. (1946). Psychoanalytic Therapy: Principles and Applications, Ronald Press Company, New York. 
Bandura, A. (1997). Self-Efficacy: the exercise of control, W.H. Freeman \& Company, ISBN 978-0716726265, New York.

Bara, G.B., Colle, L., Bosco \& F.M. (2005). Metacognizione: aspetti rilevanti per la clinica, In: Bara, B.G. (Ed.), Nuovo manuale di Psicoterapia Cognitiva, Vol. I, Bollati Boringhieri, ISBN 978-8833957685, Torino.

Bateson, G. (1972). Steps to an Ecology of Mind: Collected Essays in Anthropology, Psychiatry, Evolution, and Epistemology, University Of Chicago Press, ISBN 0226039056, Chicago.

Bateson, G., Jackson, D.D., Haley, J. \& Weakland, J. (1956). Toward a Theory of Schizophrenia, Behavioural Science, 1(4): 251-264.

Belin, D., Daniel, M.L., Lacoste, J., Belin-Rauscent, A., Bacconnier, M. \& Jaafari, N. (2011). Insight: perspectives étiologiques et phénoménologiques dans la psychopathologie des désordres obsessionnels compulsifs. Annales Médico-psychologiques, revue psychiatrique, 169(7): 420-425.

Belin, D., Mar, A., Dalley, J., Robbins, T. \& Everitt, B. (2008). High Impulsivity Predicts the Switch to Compulsive Cocaine-Taking. Science, 320(5881):1352-1355.

Belin, D., Jonkman, S., Dickinson, A., Robbins, T.W. \& Everitt, B.J. (2009). Parallel and interactive learning processes within the basal ganglia: Relevance for the understanding of addiction, Behavioural Brain Research, 199(1):89-102.

Bertalanffy, Von, L. (1969). General System Theory. Foundations, development, applications, George Braziller, ISBN 978-0807604533, New York.

Beck, A.T. (1975). Cognitive Therapy and the Emotional Disorders, International Universities Press, ISBN 978-0823609901, New York.

Braglia, D., Gerra, G., Mezzelani, P., Quaglio, G., Timpano, M.E., Zaimovic, A. \& Zambelli., U. (2004). Cocaina: Farmacocinetica, abuso, dipendenza, detossificazione e trattamento. In: Trattato completo degli abusi e delle dipendenze, Nizzoli, U. \& Pissacroia, M. (Eds.), Piccin, ISBN 978-8829916481, Padova.

Carroll, K.M., Rounsaville, B.J. \& Gawin F.H. (1991). A comparative trial of psychotherapies for ambulatory cocaine abusers: relapse prevention and interpersonal psychotherapy, The American Journal of Drug and Alcohol Abuse, 17(3):229-247.

Carroll, K.M. (1998). A Cognitive-Behavioural Approach: Treating cocaine addiction, NIH Publication 98-4308, National Institute on Drug Abuse, Rockville, Retrieved from archives.drugabuse.gov/TXManuals/CBT/CBT1.htm

Childress, A.R., Mozley, P.D., McElgin, W., Fitzgerald, J., Reivich, M. \& O’Brien, C.P. (1999). Limbic activation during cue-induced cocaine craving, American Journal of Psychiatry, 156: 11-18.

Dalley, J.W., Everitt, B.J., Robbins, T.W. (2011) Impulsivity, compulsivity, and top-down cognitive control, Neuron, 69(4):680-694.

De Shazer, S. (1985), Keys to Solutions in Brief Therapy, W.W. Norton \& Company, ISBN 978-0393700046, New York.

Di Clemente, C.C., \& Velasquez, M. (2002). Motivational Interviewing and the Stages of Change, In: Miller, W.R. \& Rollnick, S. (Eds.), Motivational Interviewing: Preparing People to Change, The Guilford Press, ISBN 978-1572305632, New York. 
Dobi, A., Seabold, G.K., Christensen, C.H., Bock, R. \& Alvarez, V.A. (2011). Cocaine-induced plasticity in the nucleus accumbens is cell-specific and develops without prolonged withdrawal, The Journal of Neuroscience, 31(5): 1895-1904.

Economidou, D., Pelloux, Y., Robbin, T.W., Dalley, J.W. \& Everitt, B.J. (2009). High impulsivity predicts relapse to cocaine-seeking after punishment-induced abstinence, Biological Psychiatry, 65(10): 851-856.

Edwards, S. \& Koob, G.F. (2010). Neurobiology of dysregulated motivational systems in drug addiction, Future Neurology, 5(3): 393-401.

Erickson, M.H. \& Rossi, E. (1981). Experiencing Hypnosis. Therapeutic Approaches to Altered States, Irvington Publishers, ISBN 0829002464, New York.

Erickson, M.H., Rossi E. \& Rossi S. (1976), Hypnotic Realities: The Induction of Clinical Hypnosis and Forms of Indirect Suggestion, Irvington Publishers, ISBN 9780829001129, New York.

European Monitoring Centre for Drugs and Drug Addiction, (2007a), EMCDDA Literature reviews - Treatment of problem cocaine use: a review of the literature, European Monitoring Centre for Drugs and Drug Addiction, ISBN 9291682748, Lisbon, Retrieved from

http://www.emcdda.europa.eu/attachements.cfm/att_44787_EN_cocainetreatme nt_literature_review.pdf

European Monitoring Centre for Drugs and Drug Addiction, (2011), 2011 Annual report on the state of the drugs problem in Europe, European Monitoring Centre for Drugs and Drug Addiction, ISBN 978-9291684700, Lisbon, Retrieved from http://www.emcdda.europa.eu/attachements.cfm/att_143743_EN_EMCDDA_AR 2011_EN.pdf

Eysenck, S.B.G., Eysenck, H.J. \& Paul Barrett, P. (1985) A revised version of the psychoticism scale, Personality and Individual Differences, 6(1):21-29.

Forsman, L., Johnson, M., Ugolini, V., Bruzzi, D. \& Raboni, D., (2003), Basic SE. Basic selfesteem scale. Valutazione dell'autostima di base negli adulti, Edizioni Erickson. ISBN 978-8879465304, Trento.

Fisch, R., Weakland, J. \& Segal, L. (1982). The Tactics of Change. Doing Therapy Briefly, Jossey-Bass, ISBN 978-0875895215, San Francisco.

Foerster, Von, H. (1982). Observing systems, Intersystems Publications, ISBN 9780914105190 Seaside.

Gazzaniga, M.S. (1972). One brain - two minds?, American Scientist, 60(3): 311-317.

Glasersfeld, Von, E. (1984). An Introduction to Radical Constructivism, In: The invented reality: How do we know what we believe we know? (Contributions to Constructivism), Watzlawick, P. (ed.), pp. 17-40, W.W. Norton \& Company, ISBN 978-0393017311, New York.

Haley, J. (1963). Strategies of psychotherapy, Grune \& Stratton, ISBN 0808901680, New York. Higgins, S.T., Wong, C.J., Badger, G.J., Odgen, D.E. \& Dantona, R.L. (2000). Contingent reinforcement increases cocaine abstinence during outpatient treatment and 1 year of follow-up, Journal of Consulting and Clinical Psychology, 68(1): 64-72.

Huang, Y.H., Lin, Y., Mu, P., Lee B.R., Brown T.E., Wayman, G., Marie, H., Liu, W., Yan, Z., Sorg, B.A., Schlüter, O.M., Zukin, R.S., \& Dong, Y. (2009). In vivo cocaine experience generates silent synapses, Neuron, 63(1): 40-47. 
Jackson, D. (1961). Interactional psychotherapy, In: Contemporary Psychotherapies, Stein, M. (Ed.), pp. 256-271, The Free Press of Glencoe, New York.

Jackson, D. (1965). The study of the family, Family Process, 4(1): 1-20.

Khantzian, E.J., Halliday, K.S. \& McAuliffe, W.E. (1990). Addiction and the vulnerable self: Modified Dynamic Group Therapy for drug abusers, Guilford Press, ISBN 9780898621723, New York.

Klerman, G.L., Weissman, M.M., Rounsaville, B.J., \& Chevron, E.S. (1984). Interpersonal Therapy of Depression, Basic Books, New York.

Lee, B.R. \& Dong, Y. (2011). Cocaine-induced metaplasticity in the nucleus accumbens: silent synapse and beyond, Neuropharmacology, 61(7): 1060-1069.

Leonardi, A., Fioravanti, P., Scavelli, S. \& Velicogna, F. (2006). Programma Conoscenza: trattamento psicoeducativo integrato ed evoluto per problemi di cocaina. In: Cocaina. Manuale di aggiornamento tecnico scientifico, Serpelloni G., Macchia T., Gerra G. (Eds.), Progetto "START" del Dipartimento Nazionale per le Politiche Antidroga, ISBN 978-8895149004, Retrieved from

http:/ /iport.dronet.org/com/filedownloadlink/allegatoA.php?key=116\&lingua=1

Leonardi, A., Fioravanti, P., Scavelli, S. \& Velicogna, F. (2009). Programma Conoscenza. Psycho-educational, integrated and evolved treatment for cocaine addiction. International Journal of Mental Health and Addiction, 7(4):513-529.

Leonardi, A. \& Velicogna, F. (2009). Cocaina: dipendenza e trattamento. Un modello di intervento psicologico, Franco Angeli, ISBN 987-8856812848, Milano.

Lewin, K. (1946), Action Research and minority problems, Journal of Social Issues, 2(4):34-46.

Main, M. (1991). Metacognitive knowledge, metacognitive monitoring and singular (coherent) vs. multiple (incoherent) models of attachment: findings and directions for future research, In: Parkes, C., Stevenson-Hinde, C.M \& Marris, P. (Eds.), Attachment across the life cycle, Tavistock \& Routledge, ISBN 0415056519, London.

Mascetti, W. \& Strepparola, G. (2006). I disturbi da uso di sostanze, In: Bara, B.G. (Ed.), Nuovo manuale di Psicoterapia Cognitiva, Vol. III, Bollati Boringhieri, ISBN 9788833957708, Torino.

Maturana, H.R. \& Varela, F.J. (1980). Autopoiesis and Cognition: the realization of the living, D. Reidel Publishing Company, ISBN 978-9027710161, Boston.

Miller, W.R. \& Rollnick, S. (2002), Motivational Interview: Preparing people to change, Guilford Press, ISBN 978-1572305632, New York.

Nardone, G. \& Watzlawick, P. (1990). L'arte del cambiamento, Ponte alle Grazie, ISBN 9788879284653, Firenze.

National Institute on Drug Abuse, (2008). Cocaine, NIDA InfoFacts, Retrieved from http://www.nida.nih.gov/pdf/infofacts/Cocaine08.pdf

Newman, C.F. \& Ratto, C.L. (1999). Cognitive therapy of substance abuse. In: Comparative treatments of substance abuse, Dowd, E.T., Rugle, L. (Eds.), Springer Publishing Company, ISBN 0826112765, New York.

O'Connell, B. \& Palmer, S. (2003). Handbook of Solution-Focused Therapy, Sage Publications, ISBN 978-0761967842, London.

Parker, G., Tupling, H., \& Brown, L.B. (1979). A Parental Bonding Instrument, British Journal of Medical Psychology, 52(1):1-10. 
Pavarin, R.M. \& Dionigi, A., (Eds.), (2009). Cocaina. Percezione del danno, comportamenti a rischio e significati, CLUEB , ISBN 978-8849133325, Bologna.

Petry, N.M. (2002). Contingency management in addiction treatment, Psychiatric Times, 19(2): 52-56.

Pirona, A. \& Hedrich, D. (2009). Treatment of cocaine use - a short update, European Monitoring Centre for Drugs and Drug Addiction, Retrieved from http://www.emcdda.europa.eu/attachements.cfm/att_76877_EN_EMCDDAcocaine $\% 20$ treatment-update.pdf

Presidenza del Consiglio dei Ministri (Eds.). (2007). Relazione sullo stato delle tossicodipendenze in Italia anno 2007, Retrieved from

http://www.governo.it/GovernoInforma/Dossier/relazione_droga_2007/Relazio ne_2007.pdf

Rigliano, P. (2004). Piaceri drogati. Psicologia del consumo di droghe, Feltrinelli, ISBN 9788807817908, Milano.

Serpelloni, G. \& Bertoncelli, S. (2006). Cocaina: profili dei soggetti in base alle modalità d'uso, agli aspetti comportamentali e sociali, In: Cocaina. Manuale di aggiornamento tecnico scientifico, Serpelloni G., Macchia T., Gerra G. (Eds.), pp. 637-653, Progetto “START" del Dipartimento Nazionale per le Politiche Antidroga, ISBN 978-8895149004, Retrieved from

http:/ /iport.dronet.org/com/filedownloadlink/allegatoA.php?key=141\&lingua=1

Shaham, Y. \& Hope, B.T. (2005a). The role of neuroadaptations in relapse in drug seeking, Nature Neuroscience, 8(11): 1437-1439.

Sluzki, C. (1966). Seminario sobre metacomunicacion: nota, Acta Psiquiatrica y Psicologica de América Latina, 12:119.

Sperry, R.W. (1968). Hemisphere deconnection and unity in conscious awareness, American Psychologist, 23(10): 723-733.

Ungless, M.A., Whistler, J.L., Malenka, R.C. \& Bonci, A. (2001). Single cocaine exposure in vivo induces long-term potentiation in dopamine neurons, Nature, 411(6837): 583587.

Watzlawick, P. (1978). The Language of Change: elements of therapeutic communication, Basic Books, ISBN 978-0465037926, New York.

Watlawick, P. (Ed.)(1984). The invented reality. How do we know what we believe we know? (Contributions to Constructivism), W. W. Norton \& Company, ISBN 9780393017311, New York.

Watzlawick, P., Beavin, J. \& Jackson, D. (1967). Pragmatics of human communication. A study of interactional patterns, pathologies and paradoxes, W. W. Norton \& Company, ISBN 978-0393010091, New York.

Watlawick, P. \& Nardone, G. (1997). Terapia Breve Strategica, Raffaello Cortina Editore, ISBN 978-8870784718, Milano.

Watlawick, P., Weakland, J., \& Fisch, J. (1974). Change. Principles of problem resolution. W. W. Norton \& Company, ISBN 978-0393011043, New York.

Weaver, T., Hart, J., Fehler, J., Metrebian, N., D'Agostino, T. \& Benn, P. (2007), Are contingency management principles being implemented in drug treatment in England?, National Treatment Agency for Substance Misuse, Retrieved from 
http://www.drugsandalcohol.ie/11939/1/NTASM_rb33_contingency_manageme nt_summary.pdf

Zuckerman, M. (1979). Sensation seeking: beyond the optimal level of arousal, L. Erlbaum, ISBN 978-0470268513, Hillsdale. 
(C) 2012 The Author(s). Licensee IntechOpen. This is an open access article distributed under the terms of the Creative Commons Attribution 3.0 License, which permits unrestricted use, distribution, and reproduction in any medium, provided the original work is properly cited. 